\title{
Análise das estratégias de financiamento e comercialização dos produtores de soja da região de Santa Rosa do Tocantins/TO1
}

Analysis of funding and marketing strategies of soybean producers of the region of Santa Rosa of Tocantins

\author{
Waldecy Rodrigues ${ }^{2}$ \\ Luécia Pereira Silva ${ }^{3}$ \\ Alivínio Almeida 4 \\ Júlio Eduardo Menezes ${ }^{5}$
}

\begin{abstract}
Resumo: Este artigo tem como objeto de análise as estratégias de financiamentos e comercialização adotadas pelos produtores de soja de Santa Rosa do Tocantins, na safra 2007/08, estabelecido por meio de contratos de compra e venda antecipada com as tradings que atendem a região. $\mathrm{O}$ estudo permitiu caracterizar os produtores quanto à origem dos créditos de financiamento, as modalidades contratuais estabelecidas entre os agentes, os fatores que motivaram os produtores a estabelecerem tais relações contratuais, bem como a influência do exercício dos contratos em suas rendas. Foram realizadas pesquisas quantitativas com 32 produtores de soja e entrevistas com gerentes de 2 tradings. As argumentações teóricas da pesquisa foram embasadas pela Economia dos Custos de Transação. Os resultados apontaram que os principais agentes de financiamento e comercialização da soja na região são as tradings; as modalidades de contratações adotadas foram as de preço fixo em real/ dólar e de preço a fixar e que $50 \%$ das contratações originadas das modalidades de preço fixo em real e/ ou dólares trouxeram prejuízo. A partir do contexto verificou-se que os contratos estabelecidos a preço fixo em real e dólar combinados com a movimentação de mercado, na liquidação dos mesmos, não caracterizaram uma boa estratégia de negócio.
\end{abstract}

Palavras chaves: contratos pré-fixados; cultivo da soja; instituições oficiais e trading.

\begin{abstract}
This paper has as object of analyzes the strategies of financings and commercialization adopted by the producers of soy of Santa Rosa of the Tocantins, in harvest 2007/08, established by means of contracts of purchase and anticipated sales with tradings that they take care of the region. The study it allowed to characterize the producers how much to the origin of the credits of financing, the established contractual modalities between the agents, the factors that had motivated the producers to establish such contractual relations, as well as the influence of the exercise of contracts in its incomes. Quantitative research with 32 producers of soy and interviews with 2 had been carried through controlling of tradings. The theoretical arguments of the research had been based by the Economy of the Costs of Transaction. The results had pointed that the main agents of financing and commercialization of the soy in the region are tradings; the modalities of adopted acts of contract had been of firm price in Real/the dollar and of 50 price to fix and that _ of the originated acts of contract of the modalities of firm price in Real and/ or dollar had brought damage. From the context it was verified that the established contracts the firm price in combined Real and dollar with the movement of market in the liquidation of the same ones did not characterize a good strategy of business.
\end{abstract}

Key Words: determinate contracts, soybean culture, officer institute and trading.

JEL: Q14.

\footnotetext{
${ }^{1}$ Artigo recebido em março de 2009 e aprovado em junho de 2009.

2 Pós-Doutor Economia (UnB). Professor do Programa de Mestrado em Desenvolvimento Regional e Agronegócio da UFT (Universidade Federal do Tocantins). E-mail: waldecy@terra.com.br

3 Aluna do Programa de Mestrado em Desenvolvimento Regional e Agronegócio da UFT. E-mail: lueciapereira@hotmail.com

${ }_{4}^{4}$ Professor do Programa de Mestrado em Desenvolvimento Regional e Agronegócio da UFT. E-mail: alivinioalmeida@uol.com.br

${ }^{5}$ Professor do Curso de Administração da UFT. E-mail: juliomenezes@uft.edu.br
} 


\section{Introdução}

O principal objetivo deste artigo é analisar as estratégias de financiamento e comercialização dos produtores de soja de Santa Rosa do Tocantins, na safra 2007/08. Estratégias estas que estão vinculadas ao estabelecimento de contratos entre os agentes do agronegócio.

Mediante a escassez e burocracia de Crédito Rural Oficial as tradings se tornaram as principais fontes de financiamento do custeio de soja no Brasil, fato também verificado na região pesquisada. Segundo Zylbersztjan (2007) ao financiar diretamente a cultura ou ao fornecer os insumos utilizados na mesma, as tradings estabelecem contratos padronizados com quantidade e preço fixados com base em um preço futuro.

Zylbersztjan (2007) relata ainda que as contratações podem ocorrer em caráter de comercialização, quando ambas as partes pretendem evitar possíveis oscilações futuras no preço do produto.

Para este estudo realizou-se pesquisa quantitativa com os produtores de soja de Santa Rosa do Tocantins e entrevistas com agentes de duas tradings que atuam na região, levantando a origem dos créditos para os financiamentos, a relação contratual estabelecida entre os agentes e a influência da liquidação dos contratos na renda dos produtores. Considerou-se também os fatores que levaram os produtores a buscar crédito fora do sistema oficial, as modalidades dos contratos e os motivos pelos quais os mesmos foram realizadas.

Para 52\% dos produtores pesquisados as tradings se resumiram na única fonte de recursos para financiamento de suas lavouras, dada à condição de restrição de crédito em que se encontravam e $20 \%$ alegaram buscar recursos financeiros fora do sistema de Crédito Rural Oficial, por não possuir garantias, estando descapitalizados devido às crises enfrentadas nas ultimas três safras 2004/ 05, 2005/ 06, 2006/ 07.

As contratações foram estabelecidas como fontes de financiamento e/ou garantia de comercialização, dentro das modalidades de preço fixo em real ou dólar e de preço a fixar, sendo constatado que $50 \%$ das contratações exercidas sobre a modalidade de preço fixo em real ou dólar trouxeram prejuízos aos produtores contratados.

Embasando pelos pressupostos da Economia dos Custos de Transação. Podese afirmar que: as transações com caráter de financiamento envolveram ativos específicos proporcionando a adoção de medidas de salvaguardas e monitoramento por parte das tradings; conforme Filho, et.all (2007) como o ambiente que envolve o agronegócio é incerto, não permitiu aos produtores prever as alterações no mercado futuro da soja; e devido ao fato de os produtores necessitarem manter o fluxo de recursos para financiamentos futuros e ao monitoramento das empresas financiadoras não houve ações oportunísticas por parte dos produtores, mesmo considerando a movimentação do mercado no momento da liquidação dos contratos.

Ao considerar o desequilíbrio entre o custo de produção e o preço de venda contratado na safra 2007/08, proporcionado pelas alterações dos mercados nacional e internacional, verificou-se que as estratégias de negociação adotadas pelos produtores não foram eficientes. Sendo necessário considerar que os contratos de compra e venda antecipada não deveria ser regra, mas apenas mais um instrumento de negociação para o produtor rural.

Considerando que o setor do agronegócio esta em constante modernização, as vistas de modificações externas e tecnológicas, gerando operações comerciais e 
financeiras estabelecidas por relações contratuais entre os agentes envolvidos. E que as relações contratuais quando a mercê de alterações climáticas e/ ou econômicas têm gerado conflitos, sendo que em alguns casos estes conflitos têm sido analisados sob ótica da Economia dos Custos de Transação (ECT), abordando a quebra contratual e pontos de fragilidade dos contratos. Aliado ao fato de que pouco tem se estudado sobre a influência destas contratações na rentabilidade e capitalização dos produtores de soja, justifica-se tal estudo.

\section{Santa Rosa do Tocantins}

Santa Rosa do Tocantins, esta situada na região sudeste do estado a uma latitude de 11026'56", longitude 480 $07^{\prime} 14^{\prime \prime}$ e altitude de 310 metros. Segundo dados IBGE (2000) o município possui 4417 habitantes, sendo que a população rural se compõe de 1994 habitantes.

O município de Santa Rosa do Tocantins é o segundo maior produtor de soja do sudeste do estado, tendo cultivado uma área de 12.000 hectares (safra 2007/2008). E por ter alcançado bons índices de produtividade, o mesmo se tornou referencial para os municípios do entorno como Natividade, Chapada da Natividade e São Valério da Natividade.

Figura 1 - Região Sudeste do Tocantins

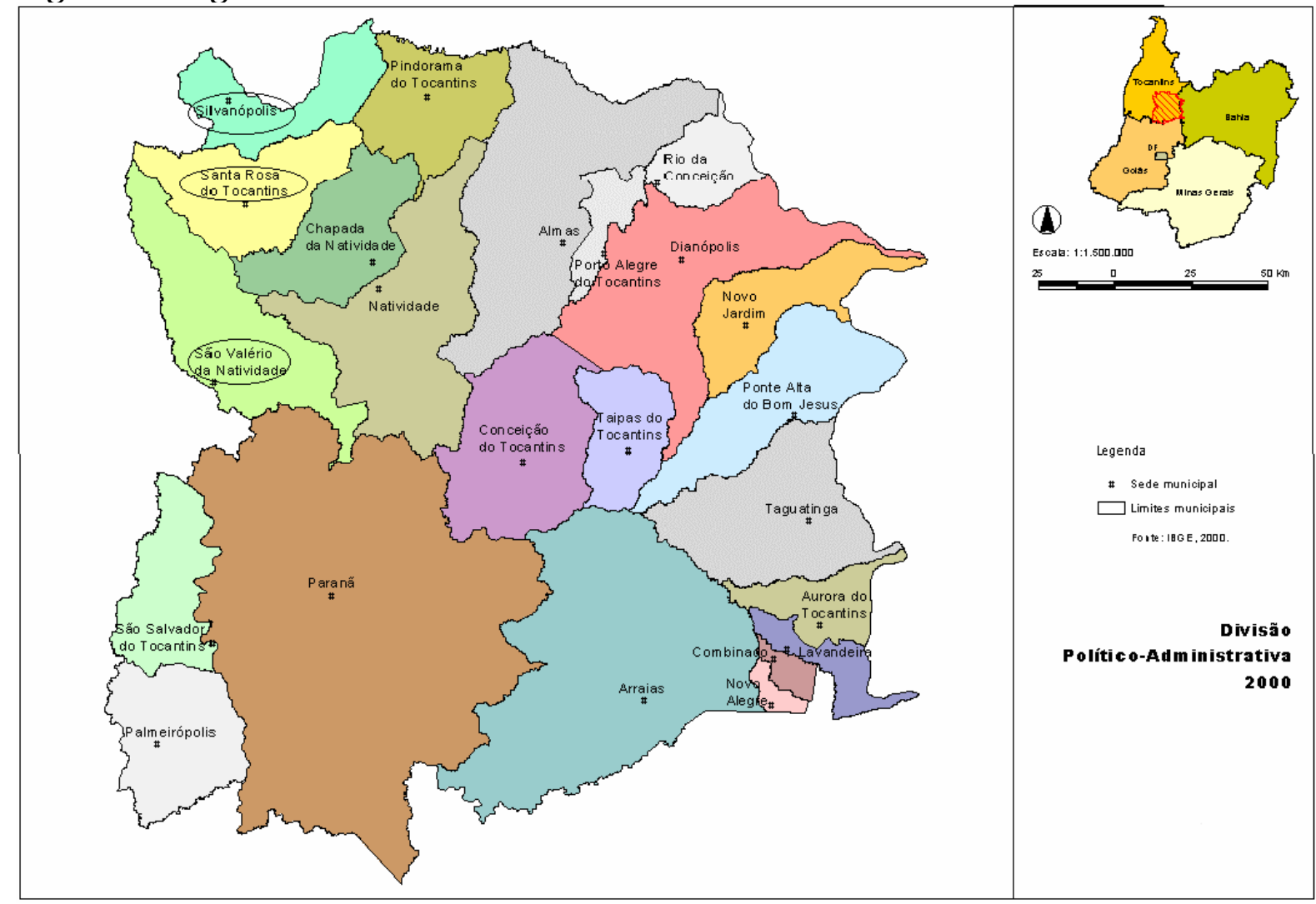

Fonte: Ferreira, et.al 2007.

A classe de solo predominante na região é o latossolo, formado pela latolização, remoção da sílica e bases de seu perfil $\left(\mathrm{Ca}^{2}+, \mathrm{Mg}^{2}+, \mathrm{K}+\right.$, etc), ocorrido 
devido ao intemperismo, realizado pela ação dos microrganismos, água, temperatura, ventos, etc. Por sofrer esta transformação esses solos se caracterizam pela grande profundidade, alta permeabilidade a água, homogenidade física e pela pequena reserva de nutrientes para as plantas (SOUZA, 2004).

Segundo Souza (2004) o fator limitante desses solos é a fertilidade, porém com aplicações de corretivos e fertilizantes, aliados as épocas propícias de plantio e cultivares adequada, obtêm-se boas produções.

O relevo é plano a suavemente ondulado. O clima da região é característico do Cerrado, com duas estações definidas: a chuvosa, no verão, que se estende de outubro a abril e a estação seca, no inverno, de maio a setembro. E temperatura média de 17 a $36^{\circ} \mathrm{C}$.

Na estação chuvosa se concentra o maior índice de precipitação, chegando a uma média anual de $1800 \mathrm{~mm}$. Pluviosidade, em geral é bem distribuída permitindo assim cultivos normais da soja, que necessita de no mínimo $700 \mathrm{~mm}$ de precipitação por ciclo (EMBRAPA ,2003).

A soja é uma leguminosa originária de regiões de clima temperado, com diversas variedades adaptadas ao clima tropical. Precisa de temperatura média entre $20^{\circ} \mathrm{C}$ a $30^{\circ} \mathrm{C}$ para o seu desenvolvimento, sendo muito exigente em fotoperíodo. Por possuir raízes pivotante e secundárias bem desenvolvidas necessita de solos bem drenados e profundos, para se desenvolver, exige controle do $\mathrm{pH}$ do solo e balanceamento dos nutrientes. Sendo assim, se caracteriza como uma cultura exigente em mecanização e tecnificação.

A agricultura se desenvolveu no município devido as condições edafoclimáticas da região que atendem as necessidades técnicas e de mecanização para cultivo da soja, a facilidade de escoamento (Santa Rosa do Tocantins situa às margens da TO 050 e próximo a uma unidade armazenadora), e as pesquisas promovidas pela EMBRAPA e Universidade Federal de Tocantins, visando encontrar variedades adaptadas à região.

\section{Sistema de Créditos}

A agricultura brasileira começou a ser tratada como pilar de sustentação da economia do país na década de 60, quando o governo institucionalizou o Crédito Rural com a Lei 4.829/65, tendo o objetivo de levar investimentos ao campo. Segundo BELIK, et.al (2001), a partir de então os financiamentos permitiram que produtores e agroindústrias se capitalizassem. Em torno do crédito rural expandiram também a assistência técnica, as pesquisas agrícolas, seguro, armazenagem e outros setores ligados à industrialização das matérias-primas vindas do campo. Neste cenário o poder publico agia como um "disciplinador" de quase todos os aspectos ligados a política agrícola (insumos, pesquisas, seguros, comercialização interna e externa,etc.).

Porém no final dos anos 70 observou-se a decadência das linhas de créditos, pois a operacionalização das mesmas apresentou sérios problemas, como a utilização discriminatória do crédito rural, o desequilíbrio entre a oferta de recursos e a demanda e a desproporção entre o elevado volume de recursos captados e a produção. O estado começa a se ausentar reduzindo seu espaço e as políticas agrícolas. Nesta faze consolidam-se os setores que conseguiram se estruturar e estabelecer fontes exclusivas de captação e gestão. Surge à integração de diferentes 
elos dos complexos agroindustriais, começa o período da auto-regulação ${ }^{6}$ (BELIK, et.al 2001).

A partir da década de 80 a agricultura passa a sofrer o desamparo da política agrícola do Governo Federal, havendo com isso a escassez do Crédito Rural. Para Belik, et. al (2001) nos meados dos anos 80, o governo deixa de intervir no setor por meio das políticas agrícola geral e setorial, exemplificando como mudança de rumo no apoio à agricultura à atuação do câmbio, que passou a ser valorizado liberando a entrada de produtos concorrentes e favorecendo a exportação. A partir de então, somente segmentos específicos passam a contar com políticas setoriais. E à medida que os mecanismos de investimentos públicos foram sendo esvaziados, seus espaços foram gradativamente preenchidos pelo sistema de crédito privado, oriundo de indústrias, trading companies e outros agentes. Vindo comprovar que apenas setores organizados conseguiram construir mecanismos de apoio e financiamento, não sofrendo a regulação do Estado. Surgindo assim um novo ambiente institucional, de governança privada.

Com a ausência de crédito do setor publico criou-se uma estreita relação entre produtores rurais e grandes corporações industriais e financeiras. Conforme afirma BELIK, et.al (2001), por trás deste movimento há uma subordinação da agricultura no sistema econômico geral e perda de rumo das associações de interesses e sindicatos agrários, gerando assim uma relação de dependência dos produtores frente as empresas.

Diante desta nova rotina de financiamentos Paulino, 2000 (apud BELIK, et.al 2001 p. 8) afirma: há uma permanente debilidade estrutural no financiamento da agropecuária brasileira, caracterizada pelas peculiaridades do processo produtivo e de sua estrutura social. Complementando Belik, et. al (2001) relata que a reestruturação do setor agroindustrial avança de acordo com interesses particulares de setores não agrários.

Atualmente esta relação esta bem caracterizada no sistema produtivo da soja, onde mecanismos de crédito privado, representados pelas trandings, financiam $67 \%$ da produção nacional de soja, sendo que conforme Castro (2005) em determinadas regiões produtoras este valor chega a $80 \%$, índice verificado na região de Balsas/ MA.

Tradings são empresas multinacionais que financiam o produtor, recebendo o pagamento em soja com fins de exportação, sendo que nesta situação os preços praticados em geral, são mais baixos que o de mercado (CASTRO, 2005).

O sistema de financiamento adotado pelas tradings é estabelecido por meio de contratos, onde há compra antecipada da produção ou parte dela, com o objetivo de financiar o cultivo da soja de forma direta ou por meio do fornecimento dos insumos agrícolas. Os contratos em geral, são padronizados tendo o preço e quantidades fixadas com base em um preço futuro. (REZENDE; ZYLBERSZTJ AN, 2007)

A relação contratual entre produtores e tradings também pode ser estabelecida sem que haja a necessidade de financiamento, motivado segundo Zilbersztjan (2007) pela necessidade das partes de evitar oscilações de preço.

As instituições oficiais, que oferecem crédito rural para custeio e investimento agropecuário, financiam entre $20 \%$ a $33 \%$ da produção brasileira, fator este proporcionado pela burocracia e a escassez de recursos.

\footnotetext{
${ }^{6}$ Auto-regulação são ações adotadas pelo governo para regulamentar o setor, como políticas de preços mínimos, aquisições do governo federal (AGF), etc. (BELIK, et.al 2001)
} 
Estas relações contratuais e seus produtos têm sido objetos de alguns atritos e geram questionamentos, principalmente quando defrontam com eventos climáticos e/ ou econômicos. Tais conflitos têm sido alvos de estudo de pesquisadores que já analisaram algumas relações contratuais, como: Contratos no Agronegócio (KHUN, et. al 2006); O Caso dos Contratos de Soja Verde (REZENDE; ZILBERSZIJ AN, 2007); Relações contratuais na cadeia produtiva da soja (FILHO,et. al 2007). Estes estudos buscam analisar os fatores impactantes da quebra de contratos bem como pontos de fragilidades dos mesmos, confrontando-os com pressupostos da Economia dos Custos de Transação.

Por outro lado pouco tem se estudado sobre a influência destas relações contratuais na rentabilidade, e por conseqüência na capitalização dos produtores rurais, que uma vez entrando nesta rotina de financiamentos e contratações criam uma relação de dependência com os agentes financiadores, conforme Belik, et. al (2001). Confrontando com dispositivos da própria Constituição Federal do Brasil que asseguram às atividades agrícolas condições para o seu desenvolvimento, tendo como exemplo o item do Artigo 187 que estabelece: “... II - preços compatíveis com custo de produção e garantia de comercialização..."; e do Estatuto da Terra, Lei 4.829/65 que traz entre outros objetivos do crédito rural: “.... II - favorecer o custeio oportuno e adequado da produção e a comercialização dos produtos agropecuários; III possibilitar o fortalecimento econômico dos produtores rurais, notadamente pequenos e médios...".

\section{Considerações Teóricas}

De acordo com MAPA, 2007 o sistema agroindustrial (SAG) da soja é um dos mais expressivos da economia brasileira. Sendo o cultivo da soja responsável por cerca de $50 \%$ da produção de grãos do país, o que confere ao Brasil ser o segundo maior produtor do mundo.

Partindo do pressuposto que os SAG's mudam com o tempo e que sempre há modificações nas relações com os agentes, por alterações externas ou mudanças tecnológicas, as relações contratuais entre os mesmos devem ser muito bem analisadas, uma vez que os agentes que atuam no sistema estabelecem uma relação de cooperação e de conflito (MAPA, 2007).

Ao se avaliar as relações contratuais estabelecidas no SAG da soja busca-se sobre a ótica da economia dos custos de transação (ECT) a análise da estrutura de governança deste sistema, a exemplo de outros estudos de SAGs: Produção e distribuição de ovos (MIZUMOTO,2004); Arroz biodinâmico (MALAFAIA;SANTOS;CAMARGO,2007).

A economia dos custos de transação (ECT) se embasa na teoria de Coase, que sugere ser a firma um complexo de contratos. Assim dizendo passa a considerar outros tipos de custos, além dos de produção: custos de transação (ZYLBERSZTJAN, 1995, p.39).

As transações, unidade analítica fundamental da economia de custos de transação (ECT), se caracterizam pela troca de bens e serviços entre os agentes econômicos.

Os custos de transação são associados ao funcionamento dos mercados (sistema de preços), incluindo assim custos de encontrar quais os preços relevantes, 
de desenho, estruturação, monitoramento e implementação dos contratos. (ZYLBERSZTJAN; NEVES, 2000). Estes custos podem ser definidos em ex-ante, referindo-se aos custos de redação, negociação e salvaguardas; e ex-post, que são os custos de monitoramento e garantia de um contrato, Milgrom (apud FILHO, et al 2007).

Zylbersztjan, (1995) relata que sobre a ótica da firma coasiana é possível indagar sobre a formatação eficiente dos contratos de forma que seu conjunto leve os agentes a cooperarem para a maximização do valor da empresa. Sendo assim é preciso compreender quais elementos se associam à formatação e desenho do contrato, direitos de propriedades, formas de monitoramento e cláusulas de ruptura contratual.

Ao se buscar formas eficientes de governança deve-se observar o alinhamento dos três grupos de fatores que condicionam tal eficiência (diminuição dos custos de transação): características das transações; ambiente institucional; pressupostos comportamentais (ZYLBERSZTJ AN; NEVES, 2000).

\subsection{Características das Transações:}

O princípio básico da teoria dos contratos é o de buscar o alinhamento entre as características das transações, características dos agentes, regidos por um determinado ambiente institucional. Este ambiente pode sofrer interferência de fatores ligados a aspectos da tradição legal, leis de proteção intelectual, tradições de disputas para a solução de disputas, aspectos culturais entre outros (ZYLBERSZTJ AN, 1995, P.25).

\subsection{Pressupostos comportamentais:}

O sistema de preços rege a alocação de recursos no mercado, e ao analisá-lo assume-se de forma implícita que os agentes nele operantes agem de forma benigna, não oportunisticamente. Também se considera a importância da incapacidade dos indivíduos em interpretar o ambiente que cerca as suas decisões, a racionalidade limitada (ZYLBERSZTJ AN; NEVES, 2000).

Para Williamson (apud ZYLBERSZTJ AN; NEVES, 2000. p.31) oportunismo é "a busca do auto-interesse com avidez", característica comportamental importante para definir a arquitetura dos contratos. Desta forma os agentes além de buscarem o auto-interesse, lançam mão de fatores como à informação privilegiada, rompendo contratos, com a finalidade de apropriar da quase renda referente à transação.

O pressuposto de ações oportunisticas leva a adoção de medidas preventivas para garantir a realização de tal contrato (salvaguardas, monitoramento, etc), mesmo que não se possa afirmar que todos os agentes são oportunistas e nem que aja assim o tempo todo, porém não se ignora que eles possam agir oportunisticamente em algum momento (ZYLBERSZTJAN; NEVES, 2000. p.31).

Zylbersztjan (1995) ainda considera que ao mesmo tempo em que se analisa a situação em que os agentes quebram os contratos visando à apropriação das quase rendas advindas de ativos específicos, podemos perguntar o que leva alguns indivíduos a não quebrarem os contratos, mesmo tendo em vista estas quase rendas. Neste contexto ele cita três razões que explicam a continuidade dos contratos: 
a) Reputação: onde o individuo é motivado a não quebrar o contrato para manter o fluxo de renda futura.

b) Garantias legais: os mecanismos punitivos instituídos pela sociedade inibem a quebra contratual de caráter oportunístico.

c) Princípios éticos: são códigos de conduta definidos por um dado grupo. Sendo que os códigos é um contrato tácito entre os agentes de difícil monitoramento.

Comportamentos oportunistas podem surgir em vários elos das cadeias agroalimentares, como no caso de uma cooperativa que após receber adiantado o pagamento de sua produção, rompe o contrato entregando apenas parte da produção ou nenhum produto (FILHO, et. al 2007).

Segundo Williansom (apud ZYLBERSZTJAN, 1995 p.17), a racionalidade limitada refere-se ao comportamento que pretende ser racional, mas consegue sê-lo apenas de forma limitada. Resulta da condição de competência cognitiva limitada de receber, estocar, recuperar e processar informação. Todos os contratos complexos são inevitavelmente incompletos devido à racionalidade limitada.

Considerando a complexidade do ambiente que cerca a decisão dos agentes e os impedem de atingir racionalidade plena, explica-se o fato de um agente agir oportunisticamente rompendo um contrato para usufruir a quase renda, enquanto que por outro lado prevendo futuras complicações que o rompimento poderia gerar, optaria pela continuidade do contrato (FILHO, et. al 2007).

Zylbersztjan relata que o conceito de racionalidade limitada leva a compreensão da importância dos atributos ex-post, nas relações contratuais.

Para Zylbersztjan (1995) a racionalidade limitada, esta ligada às características de incompletude dos contratos. E, associando a incapacidade dos agentes de prever todos os eventos possíveis às ações oportunisticas, basta que algum individuo tenha a possibilidade de agir oportunisticamente que os contratos fiquem expostos a ações que demandem salvaguardas e mecanismos de controle e monitoramento contratuais. (FILHO, et. al 2007) considera que adição destas salvaguardas contratuais aumenta o custo de preparação dos contratos, sendo responsáveis por parte considerável dos custos de transação.

\section{Metodologia}

O estudo de caso é o método de investigação mais utilizado na ECT, o qual caracteriza a presente investigação. A mesma foi baseada na seguinte pesquisa de campo:

- Qualitativa com os agentes do agronegócio

- Quantitativa com os produtores rurais

Foram entrevistados gerentes de duas tradings e trinta e dois produtores de soja da região de Santa Rosa do Tocantins, sudeste do estado, usando roteiros estruturados.

Aplicou-se 32 questionários, todos pessoalmente, aos produtores que cultivaram soja na safra 2007/08 e que obtiveram financiamento para custeio da safra em instituições financeiras oficiais e nas tradings. 
A entrevista com os gerentes das tradings teve o propósito de traçar a forma com que a empresa oferece os financiamentos e como são direcionadas as modalidades de contratos aos produtores rurais da região.

Os questionários foram aplicados aos produtores com o objetivo de se saber:

- A origem do financiamento para custeio da lavoura de soja

- Os fatores que os levam a buscar crédito fora do sistema oficial

- Se houve a realização de contratos de compra e venda antecipada

- Os fatores que os levaram a realizar os contratos de compra e venda

- A influência do exercício dos contratos em suas rendas

Com base nas entrevistas, na análise de documentos e observações de campo, foi possível associar as informações obtidas com os pressupostos teórico-conceituais da economia dos custos de transação.

\subsection{Estudo de Caso}

O caso em questão refere-se à análise das estratégias de financiamento e comercialização da safra 2007/08, dos produtores de soja de Santa Rosa do Tocantins, localizada na região Sudeste do estado. A região tem como agentes do agronegócio duas tradings e duas instituições financeiras. As tradings, assim como em todo país são os principais agentes financiadores da região e para tal firmaram contratos de compra e venda antecipada de soja com os produtores, financiando o custeio da safra e/ ou garantindo a comercialização antecipada dos grãos. O fato é que ao serem realizados a maioria dos contratos foram firmados tendo como base um preço fixo estabelecido em dólar (U\$) e/ ou real $(\mathrm{R} \$)$. E considerando o cenário econômico no momento da liquidação dos contratos pergunta-se: As estratégias de financiamento e comercialização adotados pelos produtores foram eficientes?

\section{Caracterização Contratual}

Sobre a ótica da ECT pode-se dizer que os elementos crédito e incerteza envolvem com maior peso as transações aqui analisadas.

O financiamento e/ ou comercialização caracterizados no caso em questão (contratos de compra e venda antecipada de soja) permite observar que devido ao caráter anual da cultura da soja, as contratações tem freqüência anual acontecendo a cada ano agrícola. Em sua maioria as transações são recorrentes, mostrando a dependência de grande parte dos produtores de soja em relação às tradings. Mas a reputação gerada pela recorrência não minimizou as salvaguardas. Foi observado que a dependência gerada entre os agentes permitiu a liquidação das transações.

A incerteza ambiental também reflete nos custos de transação. Segundo Filho et. al (2007) o ambiente de negócios, de forma geral, se caracteriza por ser incerto e apresentar riscos. Na relação contratual estabelecida entre os agentes financeiros e os produtores de soja de Santa Rosa do Tocantins o ambiente econômico nacional, proporcionado pela flutuação cambial e a queda do estoque de alimentos nacional e internacional contribuíram para trazer um ambiente de insatisfação em relação aos agentes envolvidos na transação, principalmente os produtores rurais. Tais fatores 
não foram previstos no ato da contratação. Porém a se precaver de ações futuras as empresas em questão estabeleceram medidas de salvaguardas no ato das contratações.

Das diferentes categorias de especificidades de ativos, três caracterizam as transações em questão: lugar, tempo e ativos dedicados. Os contratos estabelecem a entrega do produto nas unidades de armazenamento das tradings, situadas na região.

Segundo Pirrong (apud FILHO, et. al 2007) a especificidade de tempo é o atributo mais importante no caso de produtos agrícolas em razão de serem perecíveis. Considerando tal fato cláusulas determinam que os grãos colhidos devem ser entregues logo após a colheita, respeitando como período máximo à data de vencimento dos contratos. J ustifica-se ainda que as unidades de recebimento operam apenas como posto de armazenamento intermediários, daí os grãos seguem para exportação, em sua maioria, ou para processamento em outros postos, que não no Estado.

No caso dos contratos firmados com o objetivo de financiar recursos para o custeio da safra, houve antecipação do pagamento, gerando investimento por uma das partes, as tradings. Desta forma considera-se a especificidade dos ativos dedicados, exigindo salvaguardas contratuais, garantias reais, em alguns casos a propriedade rural, avais, penhor de safra, etc. e ações de monitoramento, para garantir a liquidação da transação.

Ao analisar o presente caso sobre a ótica dos pressupostos comportamentais, a racionalidade limitada se desenha mediante a incapacidade dos produtores de prever as alterações do cenário econômico nacional e internacional, no momento da contratação. Pode-se afirmar que mesmo que a maioria dos produtores contratados tenha se deparado com um ambiente diferente do que originou as contratações, no momento da liquidação dos contratos, onde houve queda na cotação do dólar (U\$) e alta mundial no preço de mercado da soja, os agentes produtores agiram sob o pressuposto da reputação dando continuidade a transação. Tal fato se explica pela intensa dependência dos produtores de soja em relação às tradings, por ser necessário manter o fluxo de financiamentos para futuras transações.

\section{Resultados}

Diante da pesquisa realizada, o Gráfico 1 mostra que dos 32 (trinta e dois) produtores entrevistados $47 \%$ afirmaram ter financiado toda sua produção com as tradings; $28 \%$ das lavouras foram totalmente financiadas pelas instituições oficiais; 9\% das lavouras de soja foram financiadas com capital próprio; $9 \%$ dos produtores complementaram os recursos adquiridos nas instituições oficiais com capitais oriundos das tradings; $3 \%$ complementaram recursos próprios com financiamentos oferecidos pelas tradings; $3 \%$ usaram recursos próprios para complementar os financiamento obtido nas instituições oficial. 
Gráfico 1- Origem do crédito para financiamento do custeio da lavoura

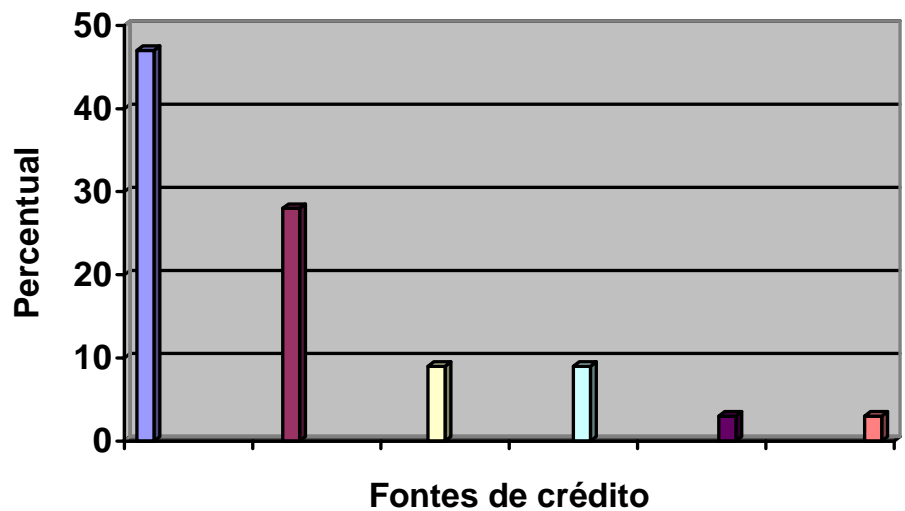

\begin{tabular}{|l|}
\hline Tradings \\
$\square$ Inst.Oficiais \\
$\square$ Próprio \\
$\square$ Inst.Oficais/Tradings \\
$\square$ Próprio/Tradings \\
$\square$ Próprio/Inst.Oficiais \\
\hline
\end{tabular}

Fonte: dados primários

Tais dados entram em conformidade com Belik (2001) que afirma que com o esvaziamento dos mecanismos de investimentos públicos seus espaços foram gradativamente preenchidos pelo sistema de crédito privado, vindos de empresas como as tradings.

O Gráfico 2 demonstra que entre os produtores que realizaram financiamento nas tradings $52 \%$ apontaram restrição ao crédito como motivo para buscar recursos financeiros fora do sistema oficial; $20 \%$ alegavam falta de garantias; $20 \%$ consideraram a facilidade na obtenção do financiamento; 8\% disseram ter outros motivos.

Gráfico 2- Fatores que motivaram a aquisição de crédito fora do sistema oficial

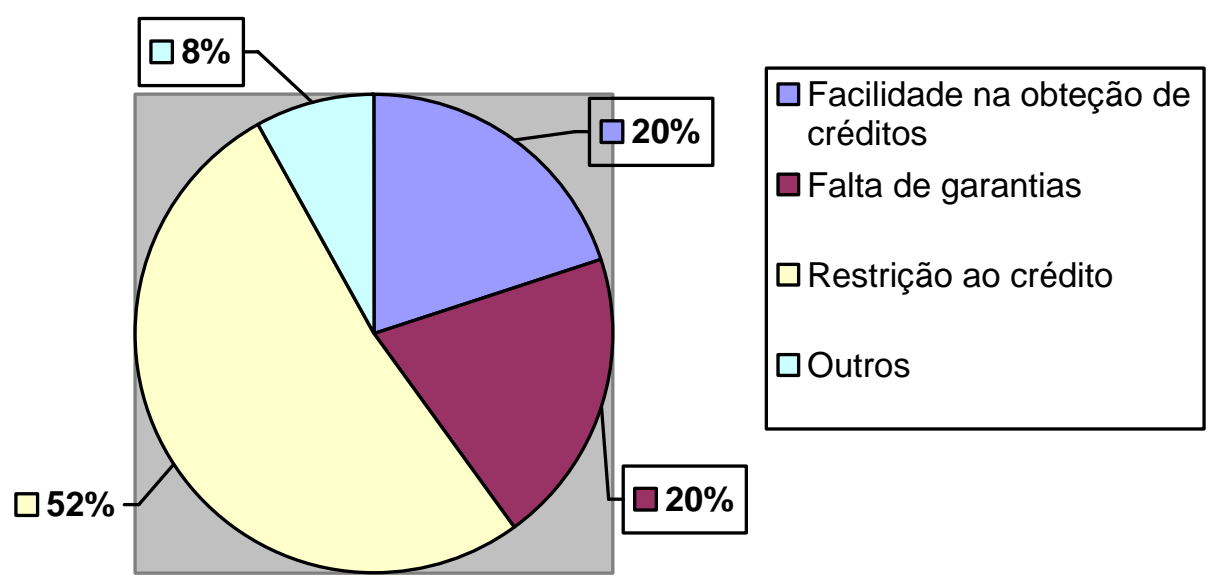

Fonte: Dados primários

Pode-se afirmar que os produtores que usaram os contratos de compra e venda antecipada como instrumentos para financiar o custeio de sua produção, em regra, estão em situação de inadimplência ou estão descapitalizados, não tendo como oferecer garantias.

A restrição ao crédito apontado com o principal motivador para a busca de crédito fora do sistema oficial é justificada pela crise agrícola que assolou o setor 
primário nas safras 2004/05, 2005/06, 2006/07, proporcionada por frustrações climáticas e alta defasagem do custo de produção em relação ao preço de venda. Agindo também na descapitalização dos produtores rurais.

A burocracia imposta pelas instituições oficiais também é citada como fator para busca de crédito fora do sistema oficial, uma vez que excessivas exigências fazem com que o crédito até então adequado à realidade dos produtores deixe de ser oportuno, não atendendo as necessidades cíclicas da atividade.

Quando questionados se foi realizado contrato de compra e venda antecipada de soja, $94 \%$ dos produtores afirmaram a contratação e 6\% declararam não ter realizado contrato, na safra 2007/ 08, conforme tabela 1.

Tabela 1 - Realização de contratos de compra e venda antecipada de soja, safra 2007/08

\begin{tabular}{lcc}
\multicolumn{1}{c|}{ Realização de contratos } & Quantidade & $\%$ \\
\hline Produtores que realizarão contratação & 30 & 94 \\
Produtores que não realizarão contratação & 2 & 6 \\
Total de produtores de soja contratados & 32 & 100 \\
\hline
\end{tabular}

Fonte: dados primários

Apenas duas tradings atuam na região, sendo que uma demonstrou preponderância com $67 \%$ das contratações; a outra trading realizou $27 \%$ dos contratos e somente $6 \%$ dos produtores contrataram com as duas empresas. O maior número de contratação se explica pela proximidade da unidade de armazenamento com a região produtora e por conseqüência maior contato entre agente financeiro e os produtores.

Conforme Tabela 2, quando questionados sobre os motivos que levaram a realização dos contratos, $41 \%$ responderam que a contratação partiu da necessidade de garantir o preço de venda; $28 \%$ contrataram para garantir o financiamento dos recursos para o custeio da lavoura; $15 \%$ disseram que realizaram os contratos por falta de informação do mercado; $8 \%$ fizeram a contratação por ter imaginado que no momento o valor contratado era bom; 8\% não souberam responder.Note que cada produtor apresenta uma ou mais justificativas, argumentando que ao mesmo tempo em que realizou a contratação para financiar o custeio da lavoura de soja tentou garantir preço de venda.

Tabela 2 - Fatores que levaram a realização de contratos de compra e venda antecipada de soja, safra 2007/08

\begin{tabular}{l|c|c}
\multicolumn{1}{c|}{ Fatores } & Quantidade & $\%$ \\
\hline Garantia de preço de venda & 16 & 41 \\
Garantia de financiamento para custeio & 11 & 28 \\
Falta de informação do mercado & 6 & 15 \\
O preço era atrativo no momento da contratação & 3 & 8 \\
N.R. & 3 & 8 \\
\hline
\end{tabular}

Fonte: dados primários.

Considerando que a firma é vista como um complexo de contratos, havendo a troca de bens e serviços entre os agentes por meio de transações (ZILBERSZTJ AN, 1995 p.39). E que o sistema de financiamento das tradings se estabelece por meio de 
contratos de compra e venda antecipada, conforme relata (REZENDE; ZILBERSZTJAN, 2007). Aliado ao fato de que as mesmas são as principais financiadoras da região, justifica-se o alto percentual de contratações entre os produtores de soja da região. Produtores que adotaram as tradings como fontes de financiamento para o custeio da lavoura, estabeleceram contratos com quantidades e preços pré-fixados direcionando partes ou toda a produção para pagamento do débito, tendo a garantia de um preço mínimo de venda.

Rezende; Zilbersztjan (2007) salientam que também são motivos para as contratações antecipadas à necessidade de ambas as partes de evitar oscilações de preço. Justificando a realização de contratos entre os produtores que tiveram recursos provenientes de outras fontes que não as tradings.

A falta de informação do mercado se embasa na incerteza ambiental, pois no ato da contratação o mercado demonstrava-se conservador garantindo o necessário para cobrir os custos de produção, naquele momento não eram acessíveis aos produtores de soja às informações da desvalorização cambial e eminente demanda mundial por alimentos. Desta forma os preços pré-fixados ofertados se apresentavam atrativos.

A Tabela 3 mostra que quando perguntados aos produtores de soja sobre qual modalidade de contratos os mesmos realizaram $75 \%$ afirmaram ter realizado contratos com preço fixo estabelecido em dólar (U\$); 17\% contrataram com preço a fixar e 8\% fizeram a contratação com preço fixo estabelecido em reais ( $\mathrm{R} \$$ ).

Tabela 3 - Modalidades de contratos

\begin{tabular}{lc}
\hline \multicolumn{1}{c|}{ Modalidades } & $\%$ \\
\hline De preço fixo e/ ou mínimo estabelecido em dólar (U\$) & 75 \\
De preço a fixar & 17 \\
De preço fixo e/ ou mínimo estabelecido em reais (R\$) & 8 \\
\hline
\end{tabular}

Fonte: dados primários

As modalidades de contratos são ofertadas e direcionadas pelas tradings, em função de uma prévia avaliação do mercado e do perfil do produtor contratado. Assim em determinado ano haverá maior ou menor direcionamento das contratações para uma ou outra modalidade. Os contratos com preços fixos estabelecidos, em real ou dólar, em geral são direcionadas a produtores que conforme avaliação de cadastro tem registros de inadimplências, pouca ou nenhuma garantia, ou seja, estão descapitalizados. Bem como quanto maior o poder de barganha do produtor maior será sua oportunidade de negociar o preço de venda.

A Tabela 4 demonstra que $93 \%$ dos produtores que afirmaram terem liquidado os contratos e $7 \%$ os liquidaram parcialmente. Os produtores que cumpriram parcialmente os contratos alegaram frustração de safra; falta de condições de recebimento e armazenamento em relação à tradings contratada.

Tabela 4 - Liquidação dos contratos

\begin{tabular}{lcc}
\multicolumn{1}{c|}{ Grau de Liquidação } & Quantidade & $\%$ \\
\hline Total & 27 & 93 \\
Parcial & 2 & 7 \\
Total de produtores de soja contratados & 29 & 100 \\
\hline
\end{tabular}

Fonte: dados primários. 
O alto percentual de liquidação dos contratos deve-se ao fato da necessidade dos produtores em financiar a futuras safras, gerando assim o pressuposto da reputação e aos mecanismos de monitoramento da produção adotado pelas tradings, ação desenvolvida junto a salvaguardas, por envolver ativos específicos, conforme relata ZILBERSZTJ AN (1995).

Quando questionados sobre a influência da liquidação dos contratos em sua renda, os produtores afirmaram que 50\% das contratações realizadas tendo como base, preços pré-fixados em real e em dólar, lhes trouxeram prejuízos. Tendo em vista a grande desvalorização do dólar na economia brasileira e a intensa valorização da soja no mercado nacional e internacional.

\section{Considerações Finais}

Neste estudo, constatou-se que tais quais as demais regiões produtoras do país as tradings são as principais financiadoras de crédito para o custeio das lavouras de soja, frente à ausência e/ ou escassez de crédito rural oficial.

Identificou-se que fatos como a restrição ao crédito, falta de garantias e a fácil obtenção de recursos são motivos alegados pelos produtores para a busca de financiamento fora do sistema oficial.

Verificou-se que a realização de contratos de compra e venda antecipada tem alta representatividade por ser a forma estabelecida, pelas tradings, de financiar e/ ou garantir a comercialização da produção.

A relação de dependência dos produtores junto às tradings, criada pela necessidade de manter o fluxo de financiamento para futuros cultivos, bem como o monitoramento exercido pelas mesmas quebrou qualquer ação de oportunismo por parte dos produtores de soja da região, mesmo considerando a defasagem entre o preço de venda contratado e o preço de mercado da produção em questão.

Ao analisar a elevada representatividade dos contratos pré-fixados em real e dólar, frente ao desempenho do mercado, na contratação e na liquidação dos mesmos, foi constatado desequilíbrio entre o preço de custo e preço de venda, gerando prejuízo em $50 \%$ das contratações. Restando afirmar que esta forma de contratação aliada à movimentação do mercado financeiro, registrada na safra 2007/08, não caracterizou uma boa estratégia de negociação por parte dos produtores de soja.

Observou-se que a estratégia de financiamento e comercialização estabelecida por meio de contratos de compra e venda antecipada não deveria ser regra, mas apenas mais um instrumento alternativo de negociação adotado pelos produtores, em face a outros mecanismos de financiamento e comercialização. Mecanismos estes que ainda são pouco acessíveis aos produtores rurais.

Dentro da lógica seria aconselhável aos produtores rurais apurarem seus custos de produção, para assim determinar a margem de lucro e estabelecer a conveniência de firmar ou não contratos. Porém, tal fato se torna impossível, diante da subordinação da maioria dos agricultores ao sistema e a debilidade da política agrícola nacional. Fica a expectativa da reversão futura da atual situação da agricultura brasileira.

Salienta-se que a profissão de agricultor é especializada, em regra só se sabe desenvolver esta atividade, e a opção de buscar financiamento junto às tradings, em 
geral esta vinculada a burocracia e escassez de crédito rural oficial, bem como ao grau de inadimplência. E mediante a esta realidade o resultado financeiro se torna irrelevante e tal profissional passa a visar à manutenção da atividade.

Frente aos resultados que esta pesquisa proporcionou surgem questionamentos, como: $\mathrm{O}$ que realmente esta por traz de tais índices de inadimplência? Qual a verdadeira dimensão da inadimplência nacional? Quais mecanismos ou ações seriam indicados para que se desenvolva a rentabilidade e a capitalização destes produtores? Com estes números a quem seria direcionado os novos investimentos anunciados pelo Governo Federal?

\section{Referências}

AGRONEGOCIO: Cadeia produtiva da soja. Brasília: MAPA/SPA. vl.2 .2007. 116 p.Disponível em: <www.agricultura.gov.br>, Acesso em: 05 ago. 2008.

\section{BELIK, W.; PAULILLO, L. F. Mudanças do financiamento da produção} agrícola brasileira.2001. p.28.

BRASIL. Constituição Federal art. 187: Da política agrícola e fundiária e da reforma agrária. 1988. Disponível em: <www.dji.com.br>, Acesso em: 14 ago. 2008.

CASTRO, J. D. B; CASTRO, M. V. D. Análise da rentabilidade de financiamento de custeios agrícolas para o cultivo de soja no pólo agrícola de Balsas - Ma. Reu. Anápolis (GO), vol. 1 nº . 1, jul/ dez. 2005. Disponível em: <www.unucseh.ueg.br>, Acesso em: 23 jul. 2008.

EMBRAPA. Tecnologia de produção de soja: região central do brasil. $1^{a}$ edição. Londrina: Embrapa soja.2003.199p.

ESTATUTO DA TERRA. Lei 4829/65. Disponível em: <www6.senado.gov.br>Acesso em: 14 ago. 2008.

FERREIRA, F. P. M; BRANDÃO, A. B. Plano estratégico de desenvolvimento regional: uma experiência para a região Sudeste do Tocantins. 2007. 21 p. Texto para discussão nํㅜ . 38. Escola de Governo da Fundação J oão Pinheiro. Belo Horizonte/MG.

FILHO, D. O. L.; SPROESSER, R. L.; TREDEZINI, C. A. O.; ANTON, E. Relações contratuais na cadeia produtiva da soja: um estudo de caso fundamentado na economia dos custos de transação. REDES, Santa Cruz do Sul, vol.12, nº. 2, p.233, mai./ ago.2007. Disponível em: <www.online.unisc.br> Acesso: 23 jul. 2008.

GASQUES, J. G.; CONCEIÇÃO, J . C.Financiamento da agricultura: dificuldades para mobilizar recursos. IPEA. $\mathrm{n}$ o 46. jul/ 99.

INSTITUTO BRASILEIRO DE GEOGRÁFIA E ESTATISTICA. Estatística população. 2007. Disponível em: <www.ibge.gov.br> Acesso: 13 ago. 2008. 
KUHN, S. L.; ROCHA J R, W. F.; STADUTO, J . A. R. Contratos no agronegócio: o caso de Cascavel, PR. 2006. 133p. Revista GEPEC, VOL. 10, №02.

MALAFAIA, G. C.; AZEVEDO, D. B.; SANTOS, A. S.; CAMARGO, M. E. Análise das relações entre produtor e agroindústria na agricultura alternativa: o caso do arroz biodinâmico. Custos e @gronegocio.v3,n1. jan/jun. 2007. Disponível em: $<w w w . c u s t o s e a g r o n e g o c i o s o n l i n e . c o m . b r>$ Acesso em: 07 ago. 2008.

MIZUMOTO, F. M. Estratégia nos canais de distribuição de ovos: análise dos arranjos institucionais simultâneos. 2004. 104 p. Tese de livre-docência Faculdade de Economia, Administração e Contabilidade, UNP, São Paulo. Disponível em: <www.Pensa.org.br>. Acesso em: 05 ago. 2008.

SOUSA, D. M. G.; LOBATO, E. Cerrado: correção do solo e adubação. Brasília: Embrapa Informação Tecnológica, 2004.

ZYLBERSZTJAN, D. Estruturas de governança e coordenação do agribusiness: uma aplicação da nova economia das instituições. 1995. 238p. Tese de livre-docência - Faculdade de Economia, Administração e Contabilidade, Universidade de São Paulo, São Paulo.

ZYLBERSZTJ AN, D.; NEVES, M. F. Economia e gestão dos negócios agroalimentares: indústria de alimentos, indústria de insumos, produção agropecuária. São Paulo: Pioneira, 2000.

ZYLBERSZTJ AN, D.; REZENDE, C. L. Pacta sunt servanda? O caso dos contratos de soja verde. 2007. 31 p. Faculdade de Economia, Administração e Contabilidade, Universidade de São Paulo, São Paulo. Disponível em: <www.Pensa.org.br>. Acesso em: 05 ago. 2008. 